\title{
Differences in Investment Concepts between Chinese and Western Investors from the Cultural Perspective
}

\author{
Zhiming Gong \\ Yunnan University, Kunming 650000, Yunnan, China \\ DOI: $10.32629 /$ memf.v2i6.594
}

\begin{abstract}
The investment concept, reflecting the investor's investment purpose and willingness, is a value that embodies the investor's investment personality characteristics, prompts investors to carry out investment analysis, judgment, decision-making, and guides investor behaviors. Due to different maturity of the capital market in China and Western countries, there are many differences in the regulatory level, cultural and behavioral patterns of the supervision and management departments of the capital market between Chinese and Western investment philosophy. This article analyzes the differences in investment ideas between Chinese and Western investors from the culture perspective. This thesis studies on the basis of four cultural differences: "The Golden Mean" and "Interest Maximization"; the face-culture and individualism; rule of man and rule of law; and gambler psychology and adventure spirit. Based on these four aspects of cultural differences, four different investment concepts of Chinese and Western investors are analyzed: long-term investments and short-term speculation; "Herd Effect" and independent decision; grapevines and public information; and leveraged trading and allocation of funds. This thesis adopts several cases to analyze the differences between Chinese and Western investors in financial products such as stocks, gold, and futures, and in investment behavior such as the long-term investment, short-term speculation, leveraged trading, and investment portfolios. With cultural differences between China and the West probed into, the differences between Chinese and Western investors' investment concepts are justified. It is hoped that this effort will help investors deepen the understanding of the capital markets in China and the West, enable Chinese investors to learn the Western mature investment concepts, and facilitate the regulators to manage the capital market effectively.
\end{abstract}

Keywords: Chinese and Western investors, investment concepts, cultural differences

\section{Long-term investments and short-term speculation}

Long-term investment and short-term speculation are two very different investment concepts, and China's "Golden Mean" thought and Western "Interest Maximization" thought have played an important role in the formation of these two kinds of investment philosophy.

\section{1 "The Golden Mean" and long-term investments}

The Doctrine of the Mean is an essay in The Book of Rites. According to the Confucian scholars, whatever they do and whomever they happen to deal with, people should always adhere to this principle. ${ }^{[1]}$ The Golden Mean is regarded as a kind of supreme realm and goal of life and morality. One of the important manifestations of The Golden Mean is the union of reason and emotion. People's pleasure, anger, sorrow and joy are the natural attributes of human beings. In order to pursue sincerity, perfection, compassion, and true humanity, it is necessary to restrict and limit emotions. This unity of rationality and sensibility is also reflected in the investment philosophy.

According to The Golden Mean, investors must manage their emotions rationally, make appropriate money, and meet their own needs. In the Chinese market, many high-net-worth customers are pursuing long-term investment and value investment with investment periods of three years, five years, and even more than ten years. These investors value the long-term development of a company, not the ups and downs of the short-term stock price. When the market conditions are good, investors are not complacent but prepared for danger in times of peace. And they are not too sad when the market is bad. Guided by The Golden Mean investment strategy, investors won't suffer too many losses. Take the listed company stock Hundsun Technologies Inc (Stock code: 600570) for example. Hundsun Technologies' stock price was about 18 yuan (rights offering price) in June 2006, and the stock price rose to about 900 yuan (rights offering price) in June 2016, reaching approximately $5000 \%$ increase in ten years.

\section{2 "Interest Maximization" and short-term speculation}

The rationalism in the West, however, follows the principle of maximization. Maximizing efficiency is the highest 
value goal for Westerners. According to an article by the doctoral student Qiaodong of Tsinghua University Rethinking the Ultimate Value Objective of Modern Western Management Thoughts, the author thinks the ultimate reason for insisting on maximizing efficiency is that it can meet the needs of maximizing the economic benefits of capitalists. ${ }^{[2]}$ In the book American Spirit: Visions of a new Corporate Culture, American management scientists Lawrence Miller thinks the capitalists regard the enterprise as a materialistic institution that does not care about human nature. Employers don't care if their employees are hungry, as long as they can make money. ${ }^{[3]}$ It can thus be seen that the nature of the capitalists is the historical source of the pursuit of the goal of maximization. Until today, the Western modern management ideology that pursues the highest goal of pursuing the maximization of economic interests has had a profound effect on modern investors.

Under the guidance of the "maximization" idea, western investors require the lowest cost and maximum profit for each investment activity. Therefore, the phenomenon of short-term investment appears in investment activities. This phenomenon is called speculation in financial terms. Speculation is the use of asymmetric information and timing to gain profits in the market. Speculative behavior focuses on price changes and rarely considers the actual value of trading instruments. Here is an example to illustrate the speculative behavior of Western speculators under the "maximization" idea.

\section{2. "Herd effect" and independent decision}

Chinese people are deeply influenced by the spirit of collectivism and pay special attention to face in daily life. Therefore, it is easy to trigger the "herd effect" in economic activities. However, in the Western culture of advocating individualism, Western investors are more inclined to independent decisions in their investment activities.

\subsection{The face-culture and herd effect}

The face-culture is an important part of traditional Chinese culture. Chinese anthropologist thinks face is a condition that one's prestige and status are recognized by the public. It is the group respects individuals who meet the standards of social moral behavior. The master of Chinese culture Linyutang thinks "face" cannot be translated or defined. "It cannot be bought with money, but it can take a kind of substantial pride to men or women. It is more precious than any other secular property, more respectable than the constitution. It is abstract and unpredictable, but it is the most delicate standard for the Chinese to regulate social interaction. Chinese people are living on this vanity."[4] In short, "face" is social, that is, individuals demand respect and recognition from society, and it is a symbol of status. At the same time, face has psychological connotation and is a kind of self-image within the personal psychology.

In the Chinese culture, collectivism has an extremely central position. This value pay attention to the harmony of interpersonal relationships, as well as the social nature of people. They do not emphasize individuals and individuality, but the role of groups. People are group-centered, and individual emotions, wishes, and privacy are insignificant compared to those of the group. People in this environment work on "face" and despise themselves to highlight others. This kind of value is in sharp contrast to the Western cultures. ${ }^{[5]}$

Nurtured in the spirit of collectivism, Chinese people pay special attention to "face". Chinese investors believe that once investment fails, they may incur laughter. When investors make investment decisions, they often pay more attention to the consequences of their actions. Once they fail, they have a greater reputational risk. Therefore, many Chinese investors often take a one-sided belief in the opinions of the people around them when they make investment decisions, because even if the investment fails, they can have better excuse and they can find psychological comfort. In terms of the behavioral finance, their behavior is manifested as "herd effect". It describes investors who have not formed their own expectations in the market or have not obtained first-hand information. Their behavior is influenced by other investors and imitates the decisions of others; or they rely too much on public opinions.

Since November 2014, the Shanghai Stock Exchange Composite Index has risen by 119\%, and the transaction volume in Shanghai and Shenzhen has created a record high of 180.25 billion yuan. During the upswing stage, the market atmosphere and the driving of capital interests have contributed to the herding effect of Chinese investors. A large number of investors have flooded into the Chinese stock market. Before the Stock market disaster happen, Chinese investors' accounts increased by 4.1 million each week. The irrational herding effect exacerbates the stock price bubble and leads to the systemic risk of the entire financial system. In June 2015, China's A-share market experienced the worst stock market crash in China's stock market so far. From June 2015 to August 2015, the Shanghai Stock Exchange Composite Index fell from a maximum of 5178 points to a minimum of 2850 points, a $44 \%$ drop in two months, and the market value of the stock market evaporated 25 trillion yuan. Herd effect is one of the most important reasons for this stock disaster.

\subsection{Individualism and independent decision}

Individualism is the traditional values of the West and it is the core of western culture. In the early days of European 
society there was a human-to-human contractual relationship. The values of individualism influence the west's spiritual culture, way of thinking, and behavior. Renaissance and Reformation in modern Europe play a very important role in the development of individualism. The Renaissance is a kind of humanist movement. Humanists at this stage considered individuals as the starting point of everything and advocated the replacement of God with human beings, with particular emphasis on the special value of individuals. The humanism of the Renaissance greatly strengthened the ideas and content of western individualism. Many writers, philosophers, and thinkers devoted themselves to the study of human thought. The German religious reformer Martin Luther's doctrine emphasizes the freedom from individualism. French enlightenment Montesquieu calls for people to maintain human dignity and humanity.

After the Renaissance and the Reformation, westerners stress the importance of self and the pursuit of human freedom. Western individualism is opposite to collectivism in China. "Individualism emphasizes personal autonomy, personal supremacy, opposition to authority, and opposition to any dominant behavior of individuals. Individuals have the right to choose freely and have the right to compete with others." ${ }^{[6]}$ The relationship between individuals reflected in individualism is symmetrical and horizontal. Western individualism advocates that all values should be based on human-centered, individuals have the highest value, individuals are the highest goals of life, and social interests are the synthesis of personal interests.

In an individual-centered Western culture, everyone has an "autonomy" personality. Individualistic western countries are tolerant to failure. Therefore, when western investors make investment decisions, their own judgment on the market is more important than the judgment of the people around them. Western investors make decisions based on their own knowledge and the correlation of judgment between investors is low. In an article Following the Pied Piper: Do Individual Returns Herd around the Market?, the authors used the dispersion index and the coefficient of regression beta $(\beta)$ to test the data of the US stock market's yield from July 1962 to December 1988. As a result, it has been found that the level of herding behavior in the U.S. market is low, which means U.S. investors are more inclined to make independent decisions, and investors' views do not tend to be market consensus. ${ }^{[7]}$

Due to the profound influence of Western individualism, compared with Chinese investors, U.S. investors are more independent in their investment decisions, and the herd effect in the U.S. market is much lower than that in the Chinese market.

\section{Conclusion}

Based on the analysis and comparison above, it is found that the investment concept of western investors is more mature than that of Chinese investors. Chinese investors are inclined to herd effects. The rational awareness of Chinese investors is not perfect, and various non-rational behaviors such as herd effect are prominent. This is not only due to the fact that there is a large gap between the maturity of the capital market in China and the western countries, but also the huge cultural differences between China and the West. It is found that in terms of investment philosophy, Chinese investors should abandon culture dross, but learn from the Western mature and rational investment ideas, and combines the realities of the Chinese capital market to obtain a considerable return on investment.

Admittedly, for a mature market investor, investors' investment decisions mainly depend on the value of the securities themselves. However, the influence of cultural differences in different regions on investors' investment decisions can not be ignored. Therefore, when the management department of the Chinese capital market makes decisions, it must not only consider the laws of economic development, but also take into account the impact of traditional culture on investors. Only in this way can the government manage the capital market effectively.

\section{References}

[1] Wang Wenjin. The Doctrine of the Mean in Universities[M]. Beijing: Zhonghua Book Company, 2008: 6-8.

[2] Qiao Dong, Li Haiyan. Reflection on the Ultimate Value Objective of Western Modern Management Thought[D]. Theoretical Guidance, 2006: 37-39.

[3] Miller, M, Lawrence. American Spirit: Visions of a new Corporate Culture[M]. New York: Warner Books, 1985.

[4] Huang Jinde. A Tentative Survey of the Cultural Differences between Chinese and Western Faces[J]. Journal of Qiongzhou University, 2009, 16(6): 81-91.

[5] Guo Zhengrong. Comparison and Analysis of "Face" in Chinese and Western Culture[J]. Journal of Xinzhou Teachers University, 2011, 27(1): 75-78.

[6] Lainé, Michaël. Can Culture Account for Investment Expectations?[J]. Journal of Economic Issues, 2016.

[7] Christie, WG. Christie. Following the Pied Piper: Do Individual Returns Herd around the Market?[J]. Financial Analysts Journal, 1995. 